\title{
Application of a 70-Gene Expression Profile to Japanese Breast Cancer Patients
}

\author{
Hideo Shimizu $^{a}$ Yoshiya Horimoto $^{a}$ Atsushi Arakawa $^{b}$ Hiroshi Sonoue $^{b}$ Mami Kurata ${ }^{a}$ \\ Taijiro Kosaka $^{a}$ Katsuya Nakai ${ }^{a}$ Takanori Himuro ${ }^{a}$ Emi Tokuda ${ }^{a}$ Yuka Takahashia \\ Fumi Taira $^{a}$ Mayuko Ito ${ }^{a}$ Ikuko Abe $^{a}$ Koji Senuma ${ }^{a}$ Lisette Stork-Sloots $^{c}$ \\ Femke de Snoo $^{\mathrm{C}}$ Mitsue Saito $^{\mathrm{a}}$
}

a Department of Breast Oncology, Juntendo University School of Medicine, Tokyo, Japan;

${ }^{b}$ Department of Human Pathology, Juntendo University School of Medicine, Tokyo, Japan;

${ }^{\mathrm{c}}$ Agendia N.V., Amsterdam, The Netherlands

\section{Keywords}

MammaPrint $\cdot$ 70-Gene expression profile $\cdot$ Breast cancer - Japanese patients · Prognosis

\section{Summary}

Background: As data on using MammaPrint ${ }^{\circledR}$, a 70-gene expression profile for molecular subtyping of breast cancer, are limited in Japanese patients, we aimed to determine the gene profiles of Japanese patients using MammaPrint and to investigate its possible clinical application for selecting adjuvant treatments. Patients and Methods: 50 women treated surgically at our institution were examined. The MammaPrint results were compared with the St Gallen 2007 and intrinsic subtype risk categorizations. Results: Of 38 cases judged to be at intermediate risk based on the St Gallen 2007 Consensus, $11(29 \%)$ were in the high-risk group based on MammaPrint. 1 of the 30 luminal A-like tumors (3\%) was judged as high risk based on MammaPrint results, whereas 7 of the 20 tumors (35\%) categorized as luminal $\mathrm{B}$-like or triple negative were in the low-risk group. There have been no recurrences to date in the MammaPrint group, and this is possibly attributable to most of the high-risk patients receiving chemotherapy that had been recommended on the basis of their MammaPrint results. Conclusions: Our results indicate that MammaPrint is applicable to Japanese patients and that it is of potential value in current clinical practice for devising individualized treatments.

\section{Introduction}

The decision to perform adjuvant chemotherapy in breast cancer patients has usually been based on risk factors for recurrence, including tumor size and lymph node metastasis [1]. However, the indications for chemotherapy are sometimes uncertain, especially in patients without lymph node involvement. Thus, the ability to identify patients who would not benefit from chemotherapy has long been a key issue. With recent advancements in genomic microarray technology, it has become possible to perform gene profiling and thereby obtain clinically useful information. van de Vijver et al. [2] developed the MammaPrint ${ }^{\circledR}$ system to evaluate the risk of breast cancer recurrence by profiling the expression levels of 70 specific genes. Using 10-year outcome data from an untreated breast cancer patient population, these 70 critical genes, which showed the highest correlation with the likelihood of distant recurrence, were chosen from among 25,000 genes for the MammaPrint profile. The ability of the 70 -gene profile to predict disease relapse has been supported by a number of retrospective studies [2-5]. The TRANSBIG Consortium showed the 70-gene profile data to be equivalent to tumor size, grade and estrogen receptor (ER) status for predicting the outcomes of node-negative patients [3]. The 70gene profile was included in the 2009 St Gallen International Expert Consensus, together with OncotypeDX, another gene profiling kit [6]. Since obtaining approval from the Food and Drug Administration in the USA, the 70-gene profile has been widely used in early breast cancer patients.

Since the concept of intrinsic subtype was introduced at the 2011 St Gallen Consensus meeting [6-9], the application of 'classical' risk factors has become increasingly rare and there has been a shift toward consideration of the response to drug therapy. While chemotherapy is generally recommended for patients who have

\section{KARGER \\ Fax +497614520714

Hideo Shimizu M.D., Ph.D. 
Table 1. Clinicopathological features of the 50 patients

\begin{tabular}{|c|c|c|c|}
\hline & \multicolumn{2}{|c|}{ MammaPrint } & \multirow[t]{2}{*}{$\mathrm{P}$ value } \\
\hline & $\begin{array}{l}\text { Low risk } \\
(n=36)\end{array}$ & $\begin{array}{l}\text { High risk } \\
(n=14)\end{array}$ & \\
\hline Mean age, years $( \pm S D)$ & $53(9.8)$ & $58(8.7)$ & 0.33 \\
\hline Mean tumor size, $\mathrm{mm}( \pm \mathrm{SD})$ & $24(7.7)$ & $21(7.4)$ & 0.96 \\
\hline \multicolumn{3}{|l|}{ Ductal } & 0.24 \\
\hline Papillotubular & $8(22 \%)$ & $2(14 \%)$ & \\
\hline Solid-tubular & $7(19 \%)$ & $6(43 \%)$ & \\
\hline Scirrhous & $14(39 \%)$ & $4(29 \%)$ & \\
\hline Lobular & $7(19 \%)$ & $2(14 \%)$ & \\
\hline Nuclear grade & & & 0.08 \\
\hline Low & $34(94 \%)$ & $12(86 \%)$ & \\
\hline High & $0(0 \%)$ & $2(14 \%)$ & \\
\hline Unknown & $2(6 \%)$ & $0(0 \%)$ & \\
\hline ER positive, \% & 97 & 71 & 0.01 \\
\hline PR positive, $\%$ & 81 & 64 & 0.07 \\
\hline \multicolumn{4}{|l|}{$\mathrm{Ki}-67^{\mathrm{a}}, \mathrm{n}$} \\
\hline$>30 \%$ & $5(14 \%)$ & $10(71 \%)$ & $<0.01$ \\
\hline$\leq 30 \%$ & $31(86 \%)$ & $4(29 \%)$ & \\
\hline$>14 \%$ & $26(72 \%)$ & $14(100 \%)$ & 0.04 \\
\hline$\leq 14 \%$ & $10(28 \%)$ & $0(0 \%)$ & \\
\hline
\end{tabular}

$\mathrm{SD}=$ Standard deviation, $\mathrm{ER}=$ estrogen receptor, $\mathrm{PR}=$ progesterone receptor . ${ }^{\mathrm{a}} \mathrm{Mean} \pm \mathrm{SD}=26.6 \pm 18.7 \%$.

triple-negative or human epidermal growth factor receptor 2 (HER2)-type tumors, physicians often encounter difficulty in selecting appropriate treatments for luminal-type tumors, as a number of clinical studies have revealed that little benefit can be expected from chemotherapy [10-13]. Thus, patient selection tools allowing avoidance of unnecessary treatment are urgently needed.

Most of the 70-gene profile studies have been conducted in European populations $[2-5,14-16]$ such that data on Asian patients are minimal $[17,18]$. In a retrospective study of 102 Japanese women, Ishitobi et al. [17] showed that the 70-gene profile accurately identified Japanese breast cancer patients at low risk of developing recurrences. The purpose of our present study was to use the 70-gene profile to determine the gene profiles of patients treated surgically at our institution. We will follow up these patients and assess the possible clinical application of the 70-gene profile for choosing adjuvant treatments.

\section{Patients and Methods}

We examined intraoperative specimens from patients with invasive breast cancer who underwent surgery during the 2-year period from November 2009 to November 2011 at our hospital. We chose patients who were clinically node negative and had tumors $>15 \mathrm{~mm}$ in diameter, to ensure an adequate tissue sample size for the 70-gene profile evaluation. We excluded patients who had received chemotherapy prior to surgery. Among clinically node-negative cases, if sentinel lymph node metastasis was detected during surgery, no further investigation was performed. We accumulated 50 cases in total for the 70-gene profile analysis. The clinicopathological features of these patients were also examined (table 1)
All fresh samples, $5 \mathrm{~mm}$ in each direction, collected intraoperatively and immediately preserved using the 70-gene profile kit generously provided by Agendia N.V., were sent to Agendia's laboratory in The Netherlands for analysis. If a sample contained invasive cancer tissue comprising less than half of the volume, the sample was judged to be inadequate. We obtained informed consent, with ethics committee approval, from all participants before sample collection.

All immunostaining results were assessed by 2 pathologists at Juntendo University Hospital. The pathological diagnosis, including tumor structure, was made according to the 'General Rules for Clinical and Pathological Recording of Breast Cancer' (ed 17) published by the Japanese Breast Cancer Society. Nuclear grade was judged using the modified Bloom-Richardson histological grades. ER and progesterone receptor (PR) status were assessed semi-quantitatively and reported as positive when $>10 \%$ of the cells in a tumor showed nuclear staining, which was the standard cut-off value at that time. The HercepTest $^{\mathrm{TM}}$ (Dako, USA) was used for the detection of HER2. HER2 overexpression was demonstrated as strong staining of the entire membrane in $>10 \%$ of the tumor cells or as weak to moderate staining, and HER2/neu amplification was confirmed by fluorescent in situ hybridization. Ki-67 was assessed in hot spots with 500-1000 cancer cells, using a mouse monoclonal antibody (Dako, USA) and reported as high when $>30 \%$ of the tumor cells showed nuclear staining.

Correlations between the 70-gene profile risk category and clinicopathological factors were assessed using the Chi-square test. Student's t-test was used to compare mean patient age and tumor size (2-tailed paired). $P$ values $<0.05$ were considered significant.

The primary endpoint of this study was the final assessment of how well the 70-gene profile evaluation results agreed with the currently used risk categorizations. The secondary endpoint was the prognostic utility of the 70-gene profile in breast cancer patients.

\section{Results}

Among the 65 patients enrolled in this study, 5 were found to have sentinel lymph node metastasis during surgery. In another 10 samples, the 70-gene profile failed due to an inadequate volume, despite our efforts to carefully choose patients and obtain samples of adequate size. Samples from the remaining 50 cases were used for the 70-gene profile analysis. The 70-gene profile classified 36 patients as low-risk and 14 as high-risk patients. All 50 cases in this study were HER2 negative. The absence of HER2-positive tumors was a consequence of registering patients in sequence according to our criteria.

\section{Relationships between the 70-Gene Profile and Tumor Grade, Ki-67 and Other Markers}

When the low- and high-risk groups according to the 70-gene profile results were compared, there were no significant differences in patient age or tumor size (table 1). In this study, we chose tumors that were clinically $>15 \mathrm{~mm}$ in diameter. Moreover, most patients with large tumors (e.g. $>50 \mathrm{~mm}$ ) were given chemotherapy before surgery. These background factors could have affected the observation that there was no difference between the low- and high-risk groups in tumor size. In the high-risk group, there were significantly more ER-negative $(p<0.05)$ and/or highly Ki-67-expressing $(p<0.01)$ tumors. When $14 \%$ was set as the cut-off value for distinguishing between luminal A-like and B-like tumors, the same trend was observed. Tumors with low Ki-67 expression were all in the low-risk group. In contrast, all tumors in the high-risk group showed a high level of Ki-67 expression. 
Table 2. Comparison of the 70-gene profile and the St. Gallen 2007 risk categorization [1]

\begin{tabular}{lcc}
\hline St. Gallen 2007 risk & \multicolumn{2}{l}{ MammaPrint } \\
\cline { 2 - 3 } categorization & Low risk $(n=36)$ & High risk $(n=14)$ \\
\hline Low risk & 9 & 3 \\
Intermediate risk & 27 & 11 \\
\hline
\end{tabular}

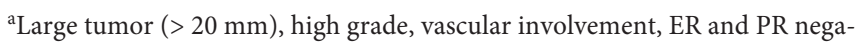
tive or young age ( $<35$ years).

Table 3. Comparison of the 70-gene profile and the intrinsic subtype classification

\begin{tabular}{lll}
\hline Intrinsic subtype & \multicolumn{2}{l}{ MammaPrint } \\
\cline { 2 - 3 } & Low risk $(n=36)$ & High risk $(n=14)$ \\
\hline Luminal A-like $_{\text {Luminal B-like }}^{\mathrm{a}}$ & 29 & 1 \\
Triple negative & 6 & 9 \\
\hline
\end{tabular}

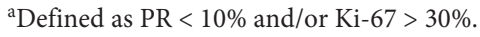

\section{Comparison with the St Gallen 2007 Risk Categorization}

We classified our 50 cases using the 2007 version of the St. Gallen risk categorization (SG 2007) [1] and compared the 70-gene profile results between women at high and low risk of recurrence (table 2). Of the 38 cases judged to be at intermediate risk based on the SG 2007, 27 (71\%) were in the low-risk group and 11 (29\%) in the high-risk group based on the 70 -gene profile.

\section{Comparison with Intrinsic Subtype Categorization Results}

Next, the results were reanalyzed using the intrinsic subtype classification [9] (table 3). In this study, luminal B-like was defined as a luminal tumor that was PR negative and/or showed high Ki-67 expression (> 30\%). The patients were categorized into 3 groups, luminal A-like, luminal B-like, and triple negative, as no patients had a HER2-type tumor. 1 of the 30 luminal A-like tumors (3\%) was judged to be in the high-risk group based on the 70-gene profile results, while 7 of 20 tumors (35\%) categorized as luminal Blike or triple negative were in the low-risk group.

\section{Discussion}

\section{Comparison of the 70-Gene Profile and the St Gallen 2007}

\section{Consensus}

Among the 38 cases with intermediate risk according to the SG 2007, 27 (71\%) were in the low-risk group based on the 70-gene profile results (table 2). These patients thus might not obtain a relevant benefit from adjuvant chemotherapy $[15,19]$. In contrast, 3 patients who were judged to be at low risk based on the SG 2007 but at high risk by the 70-gene profile might have benefited from chemotherapy.

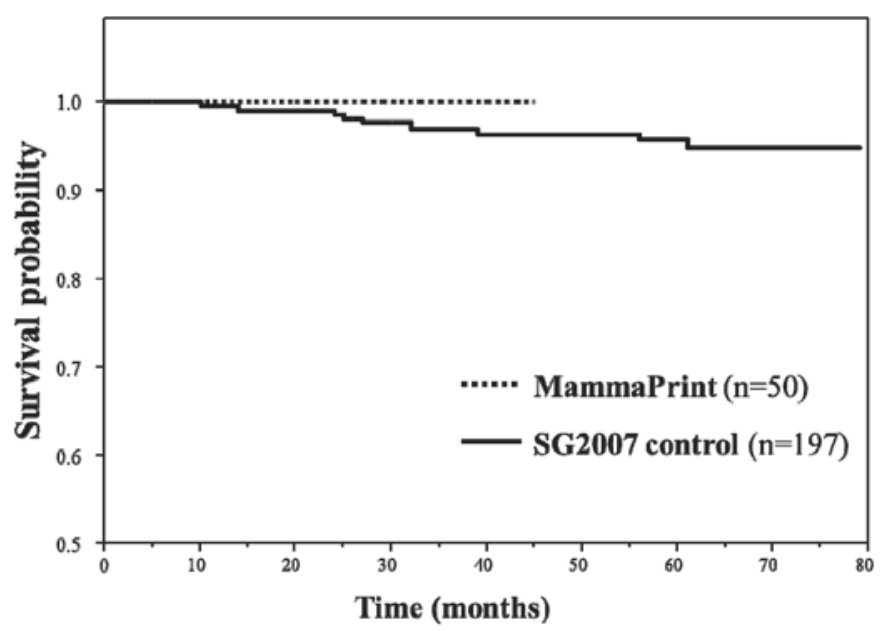

Fig. 1. All patients in the 70 -gene profile group (median follow-up period: 31 months) have remained free of recurrent disease, while 9 patients in the SG 2007 control group (58 months) developed recurrences. Kaplan-Meier curves of disease-free survival in the 70-gene profile and SG 2007 control groups. *Patients who underwent surgery between April 2007 and August 2009 and met the same requirements for the 70 -gene profile.

\section{The 70-Gene Profile and Ki-67 Expression}

In our study, being categorized as high risk by the 70 -gene profile correlated well with high Ki-67 expression. We found $60 \%$ of the luminal B-like tumors to be in the high-risk group, while only $3 \%$ of the luminal A-like tumors were considered to carry a high risk for recurrence (table 3). Focusing only on the cases with Ki-67 staining in $>50 \%$ of the cells in order to ensure that we were examining only luminal B-like tumors, there were 4 such cases and just 2 were categorized into the high-risk group. Taken together, these observations allow us to conclude that the 70-gene profile cannot be replaced by Ki-67 staining results.

\section{Contribution of the 70-Gene Profile to Patient Outcomes}

No patient in the 70-gene profile group has developed recurrent disease, to date, during a median follow-up period of 31 months. We also compared patients assessed by the 70-gene profile with those diagnosed and treated according to the SG 2007 criteria (SG 2007 control group), i.e. before the 70 -gene profile was introduced at our institution. 197 patients with invasive breast cancer meeting the same requirements for the 70-gene profile as those undergoing surgery between April 2007 and August 2009 served as a control group. HER2-positive cases were excluded from the SG 2007 control group as there were no such cases in the 70-gene profile group. The results are shown in table 4 and fig. 1.9 patients in the SG 2007 control group developed recurrent disease during a median followup period of 58 months. Significantly more patients $(71 \%)$ in the high-risk than in the low-risk 70-gene profile and SG 2007 control groups received adjuvant chemotherapy. This is presumably because doctors actively recommended these treatments, after obtaining the 70 -gene profile results. Table 4 shows how many of the patients to whom chemotherapy should have been recommended according to SG 2007 actually received these treatments. In the SG 
Table 4. Comparison of clinicopathological features between the 70-gene profile and the SG 2007 control patients

\begin{tabular}{|c|c|c|c|}
\hline & \multicolumn{2}{|c|}{ MammaPrint } & \multirow{2}{*}{$\begin{array}{l}\text { SG } 2007 \\
\text { control }^{\mathrm{a}}\end{array}$} \\
\hline & Total & High risk & \\
\hline $\mathrm{n}$ & 50 & 14 & 197 \\
\hline $\begin{array}{l}\text { Mean age, years } \\
( \pm \text { SD })\end{array}$ & $55( \pm 9.5)$ & $58( \pm 8.7)$ & $57( \pm 13.4)$ \\
\hline $\begin{array}{l}\text { Mean size, } \mathrm{mm} \\
( \pm \mathrm{SD})\end{array}$ & $24( \pm 7.5)$ & $21( \pm 7.4)$ & $24( \pm 11.4)$ \\
\hline \multicolumn{4}{|l|}{ Structure } \\
\hline Ductal & 41 & 12 & 163 \\
\hline Lobular & 4 & 1 & 8 \\
\hline Others & 5 & 1 & 26 \\
\hline \multicolumn{4}{|l|}{ Nuclear grade } \\
\hline Low & 46 & 12 & 162 \\
\hline High & 2 & 2 & 21 \\
\hline \multicolumn{4}{|l|}{ Subtype } \\
\hline Luminal type & 45 & 10 & 164 \\
\hline Triple negative & 5 & 4 & 33 \\
\hline HER2 type & 0 & 0 & 0 \\
\hline $\begin{array}{l}\text { Adjuvant } \\
\text { chemotherapy } \\
\text { regimens, n (\%) }\end{array}$ & $18(36)$ & $10(71)$ & $65(33)$ \\
\hline CEF only & 15 & 8 & 58 \\
\hline Taxane only & 2 & 2 & 0 \\
\hline $\mathrm{CEF}+$ taxane & 1 & 0 & 7 \\
\hline
\end{tabular}

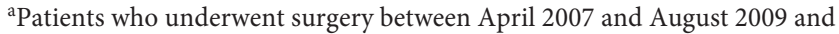
met the same requirements for the 70 -gene profile.

$\mathrm{CEF}=$ Cyclophosphamide, epirubicin, and 5-fluorouracil.

2007 control group, $38 \%$ of patients who were at intermediate risk received chemotherapy, while $61 \%$ of those in the 70 -gene profile group at intermediate risk according to the SG 2007 received such agents, indicating the impact of the 70-gene profile on treatment decision. It is possible that management strategies reflecting the 70 -gene profile results have contributed to the absence of recurrences in the 70-gene profile group, although a larger number of subjects and longer observation periods are clearly needed to make a definitive conclusion.

\section{The 70-Gene Profile in Japanese Patients}

Since most of the 70-gene profile evidence has been established in Europe $[2-5,14-16]$, there is little information pertaining to Asian patients [17, 18]. Ishitobi et al. [17] retrospectively examined 102 Japanese women using the 70 -gene profile. After a median of 7.2 years of follow-up, 12 of 82 high-risk patients developed recurrent disease, while all 20 low-risk group patients remained recurrence free. $\mathrm{Na}$ et al. [18] argued against employing criteria from Western countries for Asian patients because of racial differences. However, we believe that there is no valid reason for not using the current gene profiling methods based on possible racial differences. The only major difference in breast cancers between Asian and Westerners has been reported to be the peak age of onset, while other epidemiologic and clinical outcome data showed sig- nificant similarities [20]. In fact, treatments for our patients are determined based on the St Gallen Consensus and National Comprehensive Cancer Network guidelines. To our knowledge, this study is the first prospective investigation of the 70-gene profile in Japan. We believe that our results will allow us to confirm the validity of using the 70-gene profile in Asian patients and we plan to follow up our study subjects for 10 years.

\section{Adaptation of the 70-Gene Profile to Current Management Strategies}

The 70-gene profile was developed during the period when risk categorizations such as the SG 2007 were still in widespread use. Now, its significance is tested under the current subtype classification. As to how reliably the 70-gene profile identifies patients who would not benefit from chemotherapy, $71 \%$ (27 patients) in the intermediate group based on the SG 2007 criteria were categorized as low-risk patients based on the 70-gene profile results (table 2), while $35 \%$ (7 cases) of luminal B-like or triple-negative subtype tumors were in the low-risk group (table 3). The decrease from $71 \%$ to $35 \%$ is presumably attributable to the fact that many patients who were classified as intermediate by the SG 2007 but who did not need chemotherapy actually had luminal A-like tumors.

Recently, other gene classifiers have been developed [21, 22]. PAM50 is expected to predict late recurrence in patients with ERpositive breast cancer [21]. The 70-gene profile results were previously regarded as predicting patient outcomes, i.e. as a prognostic factor, rather than responses to treatment. However, based on the results from the TRANSBIG Consortium [3], the 70-gene profile results, in combination with subtype classification, could now serve as a factor predicting treatment responsiveness. Although final conclusions cannot be drawn until further investigations have documented long-term patient outcomes, we believe the significance of the 70-gene profile to actually be increasing. The results of ongoing trials (e.g. MINDACT) $[23,24]$ are eagerly awaited and we will continue to follow up the patients in our current study.

As to the relatively high rate of sampling failure $(17 \%, 10$ out of 60 cases), this is mainly because samples must be taken during/just after surgery in a short time, with a narrow vision at that time. This problem has been overcome owing to technological development as, at present, samples can be retrospectively carefully taken from formalin-fixed, paraffin-embedded surgical specimens.

Our results indicate the applicability of the 70-gene profile to Japanese patients and its potential value in current clinical practice for devising individualized treatments, although further follow-up is required and additional confirmatory studies using a larger sample size are needed to evaluate the significance of our results.

\section{Acknowledgments}

We appreciate Junko Ikeda at DNA Chip Research Inc. for assisting with the communication between us and Agendia N.V. and all staff members of our institute and patients who participated in this project. We also thank Dr. Edward Barroga, Associate Professor and Senior Medical Editor of Tokyo Medical University, for reviewing and editing the manuscript. 


\section{Disclosure Statement}

L.S.-S. and F.d.S. are employed by Agendia N.V., the manufacturer of MammaPrint. All other authors have no conflict of interest associated with this study.

\section{References}

1 Goldhirsch A, Wood WC, Gelber RD, Coates AS, Thürlimann B, Senn H-J: Progress and promise: highlights of the international expert consensus on the primary therapy of early breast cancer 2007. Ann Oncol 2007;18:1133-1144.

2 van de Vijver MJ, He YD, van't Veer LJ, Dai H, Hart AAM, Voskuil DW, Schreiber GJ, Peterse JL, Roberts C, Marton MJ, Parrish M, Atsma D, Witteveen A, Glas A, Delahaye L, van der Velde T, Bartelink H, Rodenhuis S, Rutgers ET, Friend SH, Bernards R: A gene-expression signature as a predictor of survival in breast cancer. New Engl J Med 2002;347:1999-2009.

$\checkmark 3$ Buyse M, Loi S, van't Veer L, Viale G, Delorenzi M, Glas AM, Saghatchian d'Assignies M, Bergh J, Lidereau R, Ellis P, Harris A, Bogaerts J, Therasse P, Floore A, Amakrane M, Piette F, Rutgers E, Sotiriou C, Cardoso F, Piccart MJ, TRANSBIG Consortium: Validation and clinical utility of a 70-gene prognostic signature for women with node-negative breast cancer. J Natl Cancer Inst 2006;98:1183-1192.

4 Bueno-de-Mesquita JM, van Harten WH, Retel VP, van't Veer LJ, van Dam FSAM, Karsenberg K, Douma KFL, van Tinteren H, Peterse JL, Wesseling J, Wu TS, Atsma D, Rutgers EJT, Brink G, Floore AN, Glas AM, Roumen RMH, Bellot FE, van Krimpen C, Rodenhuis S, van de Vijver MJ, Linn SC: Use of 70-gene signature to predict prognosis of patients with node-negative breast cancer: a prospective community-based feasibility study (RASTER). Lancet Oncol 2007;8:1079-1087.

5 Wittner BS, Sgroi DC, Ryan PD, Bruinsma TJ, Glas AM, Male A, Dahiya S, Habin K, Bernards R, Haber DA, Van't Veer LJ, Ramaswamy S: Analysis of the MammaPrint breast cancer assay in a predominantly postmenopausal cohort. Clin Cancer Res 2008; 14: 2988-2993.

6 Goldhirsch A, Ingle JN, Gelber RD, Coates AS, Thurlimann B, Senn HJ: Thresholds for therapies: highlights of the St Gallen International Expert Consensus on the Primary Therapy of Early Breast Cancer 2009. Ann Oncol 2009;20:1319-1329.

7 Goldhirsch A, Wood WC, Coates AS, Gelber RD, Thürlimann B, Senn H-J; Panel members: Strategies for subtypes - dealing with the diversity of breast cancer: highlights of the St Gallen International Expert Consensus on the Primary Therapy of Early Breast Cancer 2011. Ann Oncol 2011;22:1736-1747.
Perou CM, Sorlie T, Eisen MB, van de Rijn M, Jeffrey SS, Rees CA, Pollack JR, Ross DT, Johnsen H, Akslen LA, Fluge O, Pergamenschikov A, Williams C, Zhu SX, Lonning PE, Borresen-Dale A-L, Brown PO, Botstein D: Molecular portraits of human breast tumours. Nature 2000;406:747-752.

$\checkmark 9$ Goldhirsch A, Winer EP, Coates AS, Gelber RD, Piccart-Gebhart M, Thürlimann B, Senn H-J; Panel members: Personalizing the treatment of women with early breast cancer: highlights of the St Gallen International Expert Consensus on the Primary Therapy of Early Breast Cancer 2013. Ann Oncol 2013;24:2206-2223.

10 Andre F, Mazouni C, Liedtke C, Kau SW, Frye D, Green M, Gonzalez-Angulo AM, Symmans WF, Hortobagyi GN, Pusztai L: HER2 expression and efficacy of preoperative paclitaxel/FAC chemotherapy in breast cancer. Breast Cancer Res Treat 2008;108:183-190.

11 Huober J, Minckwitz G, Denkert C, Tesch H, Weiss E, Zahm DM, Belau A, Khandan F, Hauschild M, Thomssen C, Högel B, Darb-Esfahani S, Mehta K, Loibl S: Effect of neoadjuvant anthracycline-taxanebased chemotherapy in different biological breast cancer phenotypes: overall results from the GeparTrio study. Breast Cancer Res Treat 2010;124:133-140.

12 Straver ME, Glas AM, Hannemann J, Wesseling J, van de Vijver MJ, Rutgers EJ, Vrancken Peeters MJ, van Tinteren H, Van't Veer LJ, Rodenhuis S: The 70-gene signature as a response predictor for neoadjuvant chemotherapy in breast cancer. Breast Cancer Res Treat 2010;119:551-558.

13 Toi M, Nakamura S, Kuroi K, Iwata H, Ohno S, Masuda N, Kusama M, Yamazaki K, Hisamatsu K, Sato Y, Kashiwaba M, Kaise H, Kurosumi M, Tsuda H, Akiyama F, Ohashi Y, Takatsuka Y: Phase II study of preoperative sequential FEC and docetaxel predicts of pathological response and disease free survival. Breast Cancer Res Treat 2008;110:531-539.

14 Bueno-de-Mesquita J, Linn S, Keijzer R, Wesseling J, Nuyten D, van Krimpen C, Meijers C, de Graaf P, Bos M, Hart A, Rutgers E, Peterse J, Halfwerk H, de Groot R, Pronk A, Floore A, Glas A, van't Veer L, van de Vijver M: Validation of 70-gene prognosis signature in node-negative breast cancer. Breast Cancer Res Treat 2009;117:483-495.

15 Knauer M, Mook S, Rutgers E, Bender R, Hauptmann M, van de Vijver M, Koornstra R, Bueno-de-Mesquita J, Linn S, van't Veer L: The predictive value of the 70-gene signature for adjuvant chemotherapy in early breast cancer. Breast Cancer Res Treat 2010;120:655-661.
16 Mook S, Schmidt M, Viale G, Pruneri G, Eekhout I, Floore A, Glas A, Bogaerts J, Cardoso F, Piccart-Gebhart M, Rutgers E, van't Veer L; TRANSBIG Consortium: The 70-gene prognosis-signature predicts disease outcome in breast cancer patients with $1-3$ positive lymph nodes in an independent validation study. Breast Cancer Res Treat 2009;116:295-302.

17 Ishitobi M, Goranova TE, Komoike Y, Motomura K, Koyama H, Glas AM, van Lienen E, Inaji H, Van't Veer LJ, Kato K: Clinical utility of the 70-gene MammaPrint Profile in a Japanese population. Jap J Clin Oncol 2010;40:508-512

$18 \mathrm{Na} \mathrm{KY,} \mathrm{Kim} \mathrm{KS,} \mathrm{Lee} \mathrm{JE,} \mathrm{Kim} \mathrm{HJ,} \mathrm{Yang} \mathrm{JH,} \mathrm{Ahn} \mathrm{SH,}$ Moon BI, Kim RM, Ko SM, Jung YS: The 70-gene prognostic signature for Korean breast cancer patients. J Breast Cancer 2011;14:33-38.

19 Albain KS, Paik S, van't Veer L: Prediction of adjuvant chemotherapy benefit in endocrine responsive, early breast cancer using multigene assays. Breast 2009; 18(suppl 3):S141-S145.

20 Leong SP, Shen ZZ, Liu TJ, Agarwal G, Tajima T, Paik NS, Sandelin K, Derossis A, Cody H, Foulkes WD: Is breast cancer the same disease in Asian and Western countries? World J Surg 2010;34:2308-2324.

21 Sestak I, Dowsett M, Zabaglo L, Lopez-Knowles E, Ferree S, Cowens JW, Cuzick J: Factors predicting late recurrence for estrogen receptor-positive breast cancer. J Natl Cancer Inst 2013;105:1504-1511.

22 Naoi Y, Kishi K, Tanei T, Tsunashima R, Tominaga N, Baba Y, Kim S, Taguchi T, Tamaki Y, Noguchi S: Development of 95-gene classifier as a powerful predictor of recurrences in node-negative and ER-positive breast cancer patients. Breast Cancer Res Treat 2011;128: 633-641.

23 Cardoso F, Van't Veer L, Rutgers E, Loi S, Mook S, Piccart-Gebhart MJ: Clinical application of the 70gene profile: The MINDACT trial. J Clin Oncol 2008; 26:729-735.

24 Rutgers E, Piccart-Gebhart MJ, Bogaerts J, Delaloge S, Veer LV, Rubio IT, Viale G, Thompson AM, Passalacqua R, Nitz U, Vindevoghel A, Pierga J-Y, Ravdin PM, Werutsky G, Cardoso F: The EORTC 10041/BIG 03-04 MINDACT trial is feasible: results of the pilot phase. Eur J Cancer 2011;47:2742-2749. 